\title{
Psychological stress and transepidermal water loss in atopic dermatitis: preliminary results
}

\author{
Anna Kepska1, Marek Haftek², Audrey Nosbaum³, Pauline Pralong ${ }^{3}$, Jean-Francois Nicolas ${ }^{3}$, \\ Frederic Berard ${ }^{3}$, Alicja Ograczyk ${ }^{1}$, Anna Zalewska-Janowska ${ }^{1}$ \\ 1Psychodermatology Department, Chair of Clinical Immunology and Microbiology, Medical University of Lodz, Poland \\ Head: Prof. Anna Zalewska-Janowska MD, PhD \\ 2Laboratoire de Recherche Dermatologique, Faculté de Médecine et de Pharmacie, Université Lyon 1, France \\ Head: Prof. Marek Haftek \\ 3Service d'Immunologie Clinique et Allergologie, Centre Hospitalier Lyon Sud, INSERM Université Lyon 1, France \\ Head: Prof. Frederic Berard
}

Postep Derm Alergol 2012; XXIX, 4: 263-266

DOI: $10.5114 /$ pdia.2012.30464

\begin{abstract}
Introduction: Atopic dermatitis (AD) is an inflammatory skin disease in which activation of specific T cells directed towards environmental allergens plays an important role. Environmental allergens' penetration through the skin is facilitated by the skin barrier impairment what causes xerosis and transepidermal water loss (TEWL) increase. As $A D$ is a chronic disease, there are many factors responsible for exacerbations during the course of the disease, including environmental stress.

Aim: Evaluation of the correlation between the level of psychological stress and epidermal barrier function in AD patients.

Material and methods: Eight AD patients were included in the study during which two consultations were performed in one month's time. During each visit patients completed psychological questionnaires and had TEWL of uninvolved skin measured. The TEWL was also evaluated before and after the educational session which took place during the first visit.

Results: The study did not show any statistically significant correlation between the level of psychological stress, epidermal barrier function (measured by TEWL) and AD severity both at the beginning of the study (before and after the educational session) and a month later (all $p>0.05$ ).

Conclusions: Negative observations could result from a small number of participants and a short follow-up period. However, consecutive studies excluding these limitations may play an important role in understanding the influence of stress on the skin barrier in atopic dermatitis and have reliable clinical implications.
\end{abstract}

Key words: atopic dermatitis, transepidermal water loss, stress, education, psychodermatology.

\section{Introduction}

Atopic dermatitis (AD) is a common inflammatory skin disease of increasing prevalence in which activation of specific T cells directed towards environmental allergens plays an important role [1-3]. Environmental allergens' penetration through the skin is facilitated by the skin barrier impairment what causes xerosis and transepidermal water loss (TEWL) increase [2-5]. As AD is a chronic disease, there are many factors responsible for exacerbations during the course of the disease, including stress. In the setting of stress, sensory nerves release neuromediators regulating inflammatory and immune responses as well as the barrier function [5-8].
The AD patients and their families must cope with many serious psychosocial difficulties in addition to dealing with the medical aspects of the disease. It can cause some psychological disturbances, such as stigmatization, discrimination and social isolation. Affected individuals have been reported to suffer from anxiety, emotional excitability and depression [4, 9-12]. Health-related quality of life (HRQoL) is correlated with the disease duration: the longer the disease duration, the lower HRQoL in allergo-dermatological patients is [13]. Taking into consideration both the stress impact on the course of the disease and numerous psychological problems with which AD patients have to cope in everyday life [14], it might have

Address for correspondence: Prof. Anna Zalewska-Janowska MD, PhD, Department of Psychodermatology, Chair of Clinical Immunology and Microbiology, Medical University of Lodz, 251 Pomorska, 92-213 Lodz, Poland, phone: +48 4267573 30, +48 426757714 , fax: +48 4267822 92, e-mail: zalewska@csk.umed.lodz.pl, anna.zalewska-janowska@umed.lodz.pl 
been expected that proper holistic management involving educational sessions would have a beneficial effect not only on patients' psychological state but also on their skin condition. Although prior studies proved a significant ameliorating effect of psychological interventions on eczema severity, itch intensity and scratching behaviour in patients with $A D$, studies on coping with the impact of educational interventions on the skin barrier of these patients are still lacking [12, 15-21].

\section{Aim}

The aim of the study was to evaluate the correlation between the level of psychological stress (assessed by psychological questionnaires) and epidermal barrier function (evaluated by TEWL measurements) in AD patients and their evolution in one month's time.

\section{Material and methods}

Eight patients (2 males, 6 females) with AD diagnosed according to criteria of Hanifin and Rajka hospitalized during the "AD week" in the Service d'Immunologie Clinique et Allergologie, Centre Hospitalier Lyon-Sud in Lyon (France) were recruited. The mean age of patients was 34.6 years. None of them had any other concomitant medical disorders including dermatological, psychological and psychiatric ones.

Participation in the study of each patient involved 2 consultations. During the first visit, standard epidemiologic data were gathered with an evaluation form designed for $A D$ patients and $A D$ severity grading by the means of SCORAD Index and DLQI was performed [22, 23]. Patients completed 3 psychological questionnaires: 1) Social Readjustment Rating Scale (SRRS) by Holmes and Rahe - a list of 43 stressful life events experienced during the last year [24]; 2) The Coping Orientations to Problems Experienced Inventory (COPE) - an instrument assessing strategies of coping with stress, which distinguish between focusing on the problem, on emotions and on other people's support [25]; 3) 14-Item Perceived Stress Scale (PSS-14) - a scale measuring the degree to which situations in one's life are appraised as stressful during last month. It includes a number of direct queries about current levels of experienced stress and shows how unpredictable, uncontrollable and overloaded respondents find their lives [26].

After completing psychological questionnaires, patients had TEWL measurements in the uninvolved skin performed. The TEWL was measured using a Delfin vapometer (Delfin Technologies, Finland) in accordance with the manufacturer's instructions. As a referential place of TEWL measurements, skin of the forearm was chosen. However, because of various locations of skin lesions in $A D$ patients, the place to carry out the examination had to be adjusted to every patient separately. Patients were supposed not to apply emollients on their skin during the consultation day until they had TEWL measured.

Then, they took part in a 2-hour educational AD session led by the dermatologist, psychologist and dietician. During this session they were taught the most important facts about their disease and explained how to prevent AD exacerbations by using coping with stress strategies and proper diet. After the session, TEWL was measured once more. In the time between consecutive visits patients were supposed to use knowledge gained during the educational session, i.e. care for their skin in the proper way, change their eating habits, minimize the stress level and employ proper coping with stress strategies.

The second visit took place one month after the first one. During this visit each patient was examined with $A D$ grading and completed the same psychological questionnaires as one month earlier and had TEWL measured.

Informed consents were obtained from all patients and the study was approved by the local Ethics Committee.

\section{Results}

The study did not show any significant correlation between the level of psychological stress, methods of coping with stress used by patients, epidermal barrier function (measured by TEWL) and AD severity both at the beginning of the study (before and after the educational session) and a month later (all $p>0.05$ ). Detailed data are demonstrated in Tables 1 and 2.

\section{Discussion}

Studies applying to psychological aspects of $A D$ become more and more popular. However, even though there have been conducted studies concerning the influence of stress and psychological interventions reducing the stress level on AD patients' condition, they are usually not related to particular aspects of skin structure and function. Former studies evaluated some forms of psychotherapy like: individual behavioral therapy (which reduced significantly eczema severity and scratching behavior), group autogenic training and cognitive-behavioral therapy (significant effect on eczema severity, scratching, itching intensity and using topical steroids) and brief individual dynamic psychotherapy (positive effect on eczema severity) [12, 15-18]. Influence of structured educational programs consisted of clinical, nutritional and psychological topics (e.g. stress management, relaxation techniques) on $A D$ patients' condition in 1 year's time were evaluated by Stabb et al. in 2 studies. Both of them showed a significant effect of educational programs on the quality of life and coping strategies. However, in the study with fewer interventions and a lower number of participants there was no significant effect on eczema severity, which was observed in the second study 
Table 1. Results of clinical examination, psychological questionnaires and TEWL measurements in 1 month time evaluation

\begin{tabular}{|c|c|c|c|c|c|c|c|c|c|}
\hline \multirow[t]{2}{*}{ Parameter } & \multicolumn{5}{|c|}{ Month 1 (first visit) } & & \multicolumn{3}{|c|}{ Month 2 (follow-up) } \\
\hline & $M$ & & SD & & ME & & $M$ & SD & ME \\
\hline SCORAD & 30.30 & & 20.45 & & 7.23 & & 23.20 & 16.97 & 6.00 \\
\hline DLQI & 5.75 & & 32.50 & & 2.02 & & 7.13 & 9.34 & 3.30 \\
\hline SRRS & 152 & & 88.64 & & 31.34 & & 168.38 & 79.26 & 28.02 \\
\hline PSS & 26.75 & & 9.02 & & 3.19 & & 28 & 11.60 & 4.10 \\
\hline COPE-P & 28.38 & & 6.37 & & 2.25 & & 28.50 & 3.82 & 1.35 \\
\hline COPE-E & 26.75 & & 4.89 & & 1.73 & & 24.63 & 6.57 & 2.32 \\
\hline COPE-S & 21.13 & & 4.29 & & 1.52 & & 19.88 & 4.94 & 1.75 \\
\hline \multirow[t]{2}{*}{ TEWL } & $\mathrm{BE}$ & $\mathrm{AE}$ & BE & $\mathrm{AE}$ & $B E$ & $\mathrm{AE}$ & & & \\
\hline & 8.63 & 10.30 & 2.21 & 3.74 & 0.78 & 1.32 & 9.64 & 2.26 & 0.80 \\
\hline
\end{tabular}

SCORAD - Scoring Atopic Dermatitis, DLQI - Dermatology Life Quality Index, SRRS - Social Readjustment Rating Scale, PSS - Perceived Stress Scale, COPE - The Coping Orientations to Problems Experienced Inventory, COPE-P-focusing on problem, COPE-E - focusing on emotions, COPE-S - focusing on support, TEWL - transepidermal water loss, $M$ - mean value, SD - standard deviation, ME - standard error, BE - before educational session, AE - after educational session

$[19,20]$. Habib and Morrissey showed that taking part in the stress management program based on awareness, balance and control has a positive influence on itching intensity and social anxiety but no effect on eczema severity [21]. We found only one study concerning the correlation between psychological intervention and TEWL in AD patients in which Kimata showed that watching a humorous film significantly reduced TEWL results in elderly patients with atopic dermatitis but did not change in a healthy elderly group [27].

Our study did not show any significant correlation between the level of psychological stress and epidermal barrier function assessed by TEWL which can result from study limitations:

The main limitation of this study is a small number of recruited patients. Although it is known that some variables like age, sex, disease duration may influence skin hydration and consequently TEWL $[28,29]$ it was not possible to classify our patients depending on the aforementioned data.

Secondly, in our study we focused only on questionnaires connected with various aspects of stress in order not to make it too time-consuming and uncomfortable for patients. However, reaction to every life event, even to a few days' hospitalization or educational session depends on many personality traits like the level of neurotism, extraversion and consequently introversion, openness to new experiences, conscientiousness and temperamental traits, e.g. reactivity level. These features and previous experience may determine different reactions to the same event (stress due to the necessity to answer questions related to their health versus appeasement due to the talk with a psychologist). Therefore, it would be worth considering to include
Table 2. Results of statistical analysis employed in TEWL measurements

\begin{tabular}{lccc}
\hline TEWL & $T$ & $\boldsymbol{Z}$ & $\boldsymbol{P}$ \\
\hline $\mathrm{M}_{1} \mathrm{BE}-\mathrm{M}_{1} \mathrm{AE}$ & 7.00 & 1.94 & 0.12 \\
\hline $\mathrm{M}_{1} \mathrm{BE}-\mathrm{M}_{2}$ & 14.00 & 0.56 & 0.58 \\
\hline $\mathrm{M}_{1} \mathrm{AE}-\mathrm{M}_{2}$ & 6.00 & 1.68 & 0.09 \\
\hline
\end{tabular}

TEWL - transepidermal water loss, $M_{1}-$ month 1, $M_{2}$ - month 2, BE - before educational session, $A E$ - after educational session, $T$-test value/T-statistic, $Z$-Z-statistic, $p$ - significance level

an examination of these traits and measurement of anger, anxiety, depression and self-assessed annoyance evaluated by other authors in future studies [15, 17, 21]. It seems also to be interesting to assess the level of stress not only by means of questionnaires but also by laboratory tests, e.g. level of cortisol in saliva and immunohistochemical staining of the nerve growth factor, substance $P$, corticotrophin-releasing factor receptor and neuropeptide $Y$ which are considered to be correlated with the stress level as well.

Thirdly, the educational session comprised many elements like clinical aspects of $A D$, psychological consequences of $A D$, nutritional indications, methods of relaxation, stress coping strategies. This is the reason why it is difficult to differentiate the effect of each one on the particular subject. Therefore, studies strictly concerning every particular aspect are needed.

It is important that in the majority of previously mentioned studies, time of evaluating the patients' condition was longer than 1 month, so it is possible that in our study a longer observation would be required to obtain more conclusive results. 


\section{Acknowledgments}

Anna Kepska was supported by COST Action BM903 (STSM visit) and the Medical University of Lodz statutory grant No 503/1-137-04/503-01.

\section{References}

1. Leung DY. Atopic dermatitis: new insights and opportunities for therapeutic intervention. J Allergy Clin Immunol 2000; 105: 860-76.

2. Park KY, Kim DH, Jeong MS, et al. Changes of antimicrobial peptides and transepidermal water loss after topical application of tacrolimus and ceramide-dominant emollient in patients with atopic dermatitis. J Korean Med Sci 2010; 25: 766-71.

3. Silny W, Czarnecka-Operacz M, Gliński W, et al. Atopowe zapalenie skóry - współczesne poglądy na patomechanizm oraz metody postępowania diagnostyczno-leczniczego. Stanowisko grupy specjalistów Polskiego Towarzystwa Dermatologicznego [Polish]. Postep Derm Alergol 2010; 27 365-83.

4. Hon KL, Wong KY, Leung TF, et al. Comparison of skin hydration evaluation sites and correlations among skin hydration, transepidermal water loss, SCORAD index, Nottingham Eczema Severity Score, and quality of life in patients with atopic dermatitis. Am J Clin Dermatol 2008; 9: 45-50.

5. Suárez AL, Feramisco JD, Koo J, Steinhoff M. Psychoneuroimmunology of psychological stress and atopic dermatitis: pathophysiologic and therapeutic updates. Acta Derm Venereol 2012; 92: 7-15.

6. Lonne-Rahm SB, Rickberg H, El-Nour H, Mårin P. Neuroimmune mechanisms in patients with atopic dermatitis during chronic stress. J EurAcad Dermatol Venereol 2008; 22: 11-8.

7. Pastar Z, Lipozencić J, Ljubojević S. Etiopathogenesis of atopic dermatitis: an overview. Acta Dermatovenerol Croat 2005; 13: 54-62.

8. Karakış GP, Sin BA, Tutkak H, et al. Genetic aspect of venom allergy: association with HLA class I and class ii antigens. Ann Agric Environ Med 2010; 17: 119-23.

9. Kilpeläinen M, Koskenvuo M, Helenius H, Terho EO. Stressful life events promote the manifestation of asthma and atopic diseases. Clin Exp Allergy 2002; 32: 256-63.

10. Oh SH, Bae BG, Park CO, et al. Association of stress with symptoms of atopic dermatitis. Acta Derm Venereol 2010; 90: $582-8$

11. Howlett S. Emotional dysfunction, child-family relationships and childhoodatopic dermatitis. Br J Dermatol 1999; 140: 381-4.

12. Chida Y, Steptoe A, Hirakawa N, et al. The effects of psychological intervention on atopic dermatitis. A systematic review and meta-analysis. Int Arch Allergy Immunol 2007; 144: 1-9.

13. Świnoga $M$, Kłos M, Miniszewska J, Zalewska-Janowska A Health-related quality of life in dermatological and allergodermatological patients [Polish]. Postep Derm Alergol 2012; 29: 69-73.

14. Ograczyk A, Malec J, Miniszewska J, Zalewska-Janowska A. Psychological aspects of atopic dermatitis and contact dermatitis: stress coping strategies and stigmatization [Polish]. Postep Derm Alergol 2012; 29: 14-8.

15. Melin L, Frederiksen T, Noren P, Swebilius BG. Behavioural treatment of scratching in patients with atopic dermatitis. $\mathrm{Br}$ J Dermatol 1986; 115: 467-74.
16. Norén P, Melin L. The effect of combined topical steroids and habit-reversal treatment in patients with atopic dermatitis. Br J Dermatol 1989; 121: 359-66.

17. Ehlers A, Stangier U, Gieler U. Treatment of atopic dermatitis: a comparison of psychological and dermatological approaches to relapse prevention. J Consult Clin Psychol 1995; 63: 624-35.

18. Linnet J, Jemec GB. Anxiety level and severity of skin condition predicts outcome of psychotherapy in atopic dermatitis patients. Int J Dermatol 2001; 40: 632-6.

19. Staab D, von Rueden U, Kehrt R, et al. Evaluation of a parental training program for the management of childhood atopic dermatitis. Pediatr Allergy Immunol 2002; 13: 84-90.

20. Staab D, Diepgen TL, Fartasch M, et al. Age related, structured educational programmes for the management of atopic dermatitis in children and adolescents: multicentre, randomised controlled trial. BMJ 2006; 332: 933-8.

21. Habib S, Morrissey S. Stress management for atopic dermatitis. Behav Change 1999; 16: 226-36.

22. Severity scoring of atopic dermatitis: the SCORAD index. Consensus Report of the European Task Force on Atopic Dermatitis. Dermatology 1993; 186: 23-31.

23. Finlay AY, Khan GK. Dermatology Life Quality Index (DLQI); a simple practical measure for routine clinical use. Clin Exp Dermatol 1994; 19: 210-6.

24. Holmes $\mathrm{TH}$, Rahe $\mathrm{RH}$. The Social Readjustment Rating Scale. J Psychosom Res 1967; 11: 213-8.

25. Strelau J. Psychology. Academic book 3. Human in society and elements of applied psychology [Polish]. GWP, Gdansk 2002.

26. Cohen S, Kamarck T, Mermelstein R. A global measure of perceived stress. J Health Soc Behav 1983; 24: 385-96.

27. Kimata $H$. Elevation of testosterone and reduction of transepidermal water loss by viewing a humorous film in elderly patients with atopic dermatitis. Acta Medica (Hradec Kralove) 2007; 17: 135-7.

28. Cua AB, Wilheim KP, Maibach HI. Erictional properties of human skin: relations to age, sex and anatomical region, stratum corneum hydration and transepidermal water loss. Br J Dermatol 1990; 123: 473-9. 